\title{
THE EFFECT OF COLD ROLLING ON THE CREEP BEHAVIOR OF INCONEL $®$ ALLOY 718
}

\author{
C.J. Boehlert ${ }^{1}$, D.S. Dickmann ${ }^{2}$, and N.C. Eisinger ${ }^{3}$ \\ ${ }^{1}$ Michigan State University, East Lansing, MI \\ ${ }^{2}$ Ferro Corporation, Rochester, NY \\ ${ }^{3}$ Special Metals Corporation, Huntington, WV
}

Keywords: microstructure, creep, backstress, creep rupture

\begin{abstract}
The creep behavior of INCONEL ${ }^{\circledR}$ alloy 718 (IN 718) was investigated to identify processingcreep property relationships. The alloy was cold rolled (CR) to $0,10,20,30,40,60$, and $80 \%$ followed by annealing and aging. In addition, this alloy can be superplastically formed (IN $718 \mathrm{SPF}$ ) to a significantly finer grain size and the corresponding microstructure and creep behavior were evaluated. The creep behavior was evaluated in the applied stress range of 300$758 \mathrm{MPa}$ and the temperature range of $638-670^{\circ} \mathrm{C}$. Constant-load tensile-creep experiments were used to measure the values of the steady-state creep rate and the consecutive load reduction method was used to determine the values of backstress $\left(\sigma_{\mathrm{o}}\right)$. Creep-rupture time $\left(\mathrm{T}_{\mathrm{r}}\right)$ and elongation-to-failure $\left(\varepsilon_{\mathrm{f}}\right)$ were also evaluated at $649^{\circ} \mathrm{C}$ and $758 \mathrm{MPa}$. The lowest $\sigma_{\mathrm{o}}$ values $\left(300 \mathrm{MPa}<\sigma_{0}<310 \mathrm{MPa}\right)$ were exhibited for the most severely CR microstructures $(60 \%, 80 \%$, and IN 718SPF), while the baseline $0 \% \mathrm{CR}$ microstructure exhibited a significantly greater $\sigma_{0}$ value $(540 \mathrm{MPa})$. The greatest $\sigma_{0}$ values, 645 and $630 \mathrm{MPa}$, were exhibited by the $20 \%$ and $30 \% \mathrm{CR}$ conditions, respectively. The $\sigma_{\mathrm{o}}$ values were related to the overall creep resistance as the $20 \% \mathrm{CR}$ condition exhibited the lowest secondary creep rates for a given applied stress $\left(\sigma_{\mathrm{a}}\right)$, while the samples CR to more than $40 \%$ exhibited the greatest creep rates. The values for the effective stress exponent suggested that the transition between the rate-controlling creep mechanisms was dependent on effective stresses $\left(\sigma_{\mathrm{e}}=\sigma_{\mathrm{a}}-\sigma_{0}\right)$ and the transition occurred at $\sigma_{\mathrm{e}}=135 \mathrm{MPa}$ for a temperature of $638^{\circ} \mathrm{C}$. Increased $\mathrm{CR}$ tended to increase $\mathrm{T}_{\mathrm{r}}$ and $\varepsilon_{\mathrm{f}}$, and the $30 \% \mathrm{CR}$ condition exhibited the greatest creep rupture properties. Overall, the $20 \% \mathrm{CR}$ and $30 \% \mathrm{CR}$ microstructures exhibited the greatest creep strength, while the most severely CR materials exhibited the poorest creep strength.
\end{abstract}

\section{Introduction}

In order to identify processing-creep property relationships, the current work evaluated the creep behavior of IN 718 as a function of sheet processing using $10 \%$ cold-rolling increments from $0-80 \%$ followed by annealing and aging, and the tensile-creep properties were measured. The approach taken was to characterize the creep behavior within the low-stress creep regimes where diffusional creep and grain boundary sliding may be dominating the strain rate response, and in addition the creep backstress was measured as a function of the amount of CR deformation.

\footnotetext{
${ }^{\circledR}$ INCONEL is a registered trademark of Special Metals Corporation.
} 
The creep mechanisms that operate during elevated-temperature deformation of pure metals and solid-solution strengthened alloys have been related to the value of the stress exponent, $\mathrm{n}_{\mathrm{a}}$, and the apparent activation energy, $\mathrm{Q}_{\mathrm{a}}$, in the Dorn steady-state creep rate equation $[1]:$

$$
\dot{\varepsilon}_{\mathrm{ss}}=\mathrm{A} \mathrm{D} \mathrm{D}_{\mathrm{o}} \exp \left(-\mathrm{Q}_{\mathrm{a}} / \mathrm{RT}\right) \mu \mathrm{b} / \mathrm{kT}\left(\sigma_{\mathrm{a}} / \mu\right)^{\mathrm{n}_{\mathrm{a}}}
$$

where $\mathrm{T}$ is the creep temperature in degrees Kelvin, $\mathrm{R}$ is the gas constant, and $\mathrm{A}$ is often referred to as the Dorn constant, $\mathrm{b}$ is the Burger's vector, $\mathrm{D}_{\mathrm{o}}$ is the pre-exponential factor, $\mu$ is the shear modulus, and $\mathrm{k}$ is the Boltzmann constant. However, the $\mathrm{n}_{\mathrm{a}}$ and $\mathrm{Q}_{\mathrm{a}}$ values measured for alloys containing dispersed second-phase particles are generally considerably greater than those observed in pure metals and solid solution strengthened alloys [2-14]. The $\mathrm{n}_{\mathrm{a}}$ values for precipitation-hardened alloys have ranged between 5-15 [2-7] while, for dispersion-hardened alloys, including thoria dispersed $\mathrm{Ni}-20 \mathrm{Cr}(\mathrm{wt} . \%), \mathrm{n}_{\mathrm{a}}$ values have ranged between 9-75 $[10,13,14]$. The $\mathrm{Q}_{\mathrm{a}}$ values have ranged from one to three times those of the activation energy for self diffusion [12,14,15]. These variations in the observed values of $n_{a}$ and $Q_{a}$ have been rationalized by introducing the concept of a backstress or threshold stress, $\sigma_{\mathrm{o}}$, which is an internal stress opposing the dislocation motion. In multiphase alloys such as IN 718, which contains an austenitic FCC phase matrix $(\gamma)$ and fine $\gamma^{\prime}$ and $\gamma^{\prime \prime}$ strengthening precipitates, the applied stress during steady-state creep deformation is opposed by a backstress resulting from the presence of these strengthening particles and a defect structure within the material $[2,10,16-$ 21]. Therefore, the creep deformation results from an effective stress $\left(\sigma_{\mathrm{e}}=\sigma_{\mathrm{a}}-\sigma_{\mathrm{o}}\right)$. As a result, the steady-state creep rate can be represented by:

$$
\dot{\varepsilon}_{\mathrm{ss}}=\mathrm{A}^{*}\left(\sigma_{\mathrm{a}}-\sigma_{\mathrm{o}}\right)^{\mathrm{n}_{\mathrm{e}}}
$$

where $n_{e}$ is the effective stress exponent. Although traditionally used to measure the backstress during high-stress dislocation power-law creep, it has been shown that the consecutive stress reduction method can also be applied to low-stress diffusional creep for IN 718 where low $\mathrm{n}_{\mathrm{e}}$ values are observed $[16,17]$.

\section{Experimental}

The IN 718 sheets used in this study were processed at Special Metals Corporation, Huntington, WV. The heats were produced by vacuum induction melting followed by electroslag remelting. The material was hot worked using conventional practices and the asprocessed condition included mill annealing at $1066^{\circ} \mathrm{C}$ for all hot-rolling procedures which preceded the final $\mathrm{CR}$ and $982^{\circ} \mathrm{C}$ anneal. Subsequent thermomechanical processing treatments included CR between 10-80\%. The CR steps were performed on separate sheets each designated with $10 \%, 20 \%, 30 \%, 40 \%, 60 \%$, and $80 \%$ deformation. The annealing treatment was performed at 954,1010 , or $1050^{\circ} \mathrm{C}$. In addition, one set of CR samples was heat treated below the recrystallization temperature at $871^{\circ} \mathrm{C}$. The aging treatment, used to precipitate out the $\gamma^{\prime}$ and $\gamma^{\prime \prime}$ strengthening phases, consisted of $718^{\circ} \mathrm{C} / 8 \mathrm{~h} /$ furnace cool to $621^{\circ} \mathrm{C}$ then hold at $621^{\circ} \mathrm{C}$ for a total aging time of $18 \mathrm{~h}$. In addition, a separate heat of IN $718 \mathrm{SPF}$ was produced in a similar fashion, however the sheet cold working procedure, estimated to total between 55-80\% deformation, was altered to assure the production of an ultrafine grain size product [22-25].

Flat dogbone-shaped tensile-creep specimens, with a cross-section of approximately $1 \mathrm{mmx} 12 \mathrm{~mm}$ and a gage length of $25 \mathrm{~mm}$, were machined, using either a mill or an electrodischarge machine, with the tensile axis parallel to the rolling direction. Constant-load creep experiments were performed on an Applied Test Systems, Incorporated (ATS) lever-arm 
creep apparatus, using a 20:1 load ratio, in air at temperatures ranging between $638-670^{\circ} \mathrm{C}$ and applied stresses ranging between $300-758 \mathrm{MPa}$. The creep strain was monitored during the tests using a linear variable differential transformer attached to the gage section. The specimen temperature, monitored by three thermocouples located within the gage section during the creep experiments, was maintained within $\pm 3^{\circ} \mathrm{C}$ using a single-zone ATS furnace. The $\sigma_{o}$ values were determined at $638^{\circ} \mathrm{C}$ by the consecutive stress reduction method $[2,5,9]$. When the creep rate for a given $\sigma_{\mathrm{a}}$ remained constant for at least five hours, it was assumed the steady-state creep rate had been achieved. Thereafter, the sample was subjected to a small stress reduction (approximately $5 \% \sigma_{\mathrm{a}}$ ). This resulted in an elastic contraction of the sample, followed by an incubation period with a zero creep rate. After a period of time, creep began again at a lower rate. Once steady state was reached, another stress reduction was performed. The time of the incubation period following each stress reduction was recorded. The remaining stress vs. the cumulative incubation time was plotted, and $\sigma_{0}$ was determined by taking the asymptotic value of the remaining stress when the cumulative incubation time appeared to be infinite. The $\sigma_{\mathrm{o}}$ and $\varepsilon_{\mathrm{ss}}$ values proved to be repeatable as duplicate samples were tested at the same temperature and $\sigma_{\mathrm{a}}$ and the measured $\varepsilon_{\mathrm{ss}}$ values were within five percent of each other. In addition, the $\sigma_{\mathrm{o}}$ and $\dot{\varepsilon}_{\mathrm{ss}}$ values were not dependent on strain history for total creep strains less than $0.5 \%$ as several temperature/applied stress conditions were performed, some in duplicate, before that of the backstress condition and in each case similar $\sigma_{0}$ values were recorded. Creep rupture experiments were performed in air at $758 \mathrm{MPa}$ and $649^{\circ} \mathrm{C}$. All the creep experiments were initiated after soaking the samples at the desired testing temperature for a minimum of 0.5 hours to equilibrate the thermal stresses.

\section{Results}

\section{$\underline{\text { Microstructure }}$}

The chemical composition range of the IN 718 heats used is shown in Table I. The annealed microstructures contained an equiaxed $\gamma$-phase austenitic matrix and after aging fine $\gamma^{\prime}$ (coherent spherical fcc $\left(\mathrm{L}_{12}\right)$ ) and $\gamma^{\prime}$ (coherent ordered disc-shaped body-centered tetragonal $\left(\mathrm{DO}_{22}\right)$ ) precipitated throughout, see Figure 1. The average $\gamma$ grain diameter for the $0-40 \% \mathrm{CR}$ sheets ranged between $16-20 \mu \mathrm{m}$ as measured through the line-intercept method. Thus $0-40 \% \mathrm{CR}$ did not drastically change the equiaxed $\gamma$ grain size. However, the $60 \% \mathrm{CR}, 80 \% \mathrm{CR}$, and IN $718 \mathrm{SPF}$ microstructures exhibited an average grain diameter of $6.6 \mu \mathrm{m}$. Annealing temperature had a significant effect on grain size. Above $1010^{\circ} \mathrm{C}$, grain growth occurs [26] and the $1050^{\circ} \mathrm{C}$, onehour annealed samples exhibited a grain diameter of $45 \mu \mathrm{m}$. It is noteworthy that the roomtemperature strength and hardness values significantly increased with CR deformation for the $871^{\circ} \mathrm{C}$ heat-treated samples, while hardness remained almost constant after $954^{\circ} \mathrm{C}$ annealing. This indicated that $871^{\circ} \mathrm{C}$ is below the austenite $(\gamma$-phase) recrystallization temperature for 0 $40 \% \mathrm{CR}$ IN 718, which is consistent with previous findings [27]. The relatively constant hardness values for the $954^{\circ} \mathrm{C}$ annealed samples indicated that the annealing temperature was above the recrystallization temperature.

Table I. Composition range for the IN 718 heats used in this study

\begin{tabular}{|c|c|c|c|c|c|c|c|}
\hline Element & $\mathrm{Ni}$ & $\mathrm{Ti}$ & $\mathrm{Mo}$ & $\mathrm{Co}$ & $\mathrm{Cr}$ & $\mathrm{Al}$ & $\mathrm{P}$ \\
\hline Weight percent & $53.68-53.48$ & $1.01-1.06$ & 2.99 & $0.03-0.12$ & $18.1-18.4$ & $0.46-0.48$ & $0.009-0.012$ \\
\hline Element & $\mathrm{C}$ & $\mathrm{Fe}$ & $\mathrm{Cu}$ & $\mathrm{Si}$ & $\mathrm{Mn}$ & $\mathrm{Nb}$ & $\mathrm{S}$ \\
\hline Weight percent & 0.03 & $17.99-18.3$ & $0.02-0.17$ & $0.01-0.17$ & $0.04-0.12$ & $5.07-5.11$ & 0.001 \\
\hline
\end{tabular}




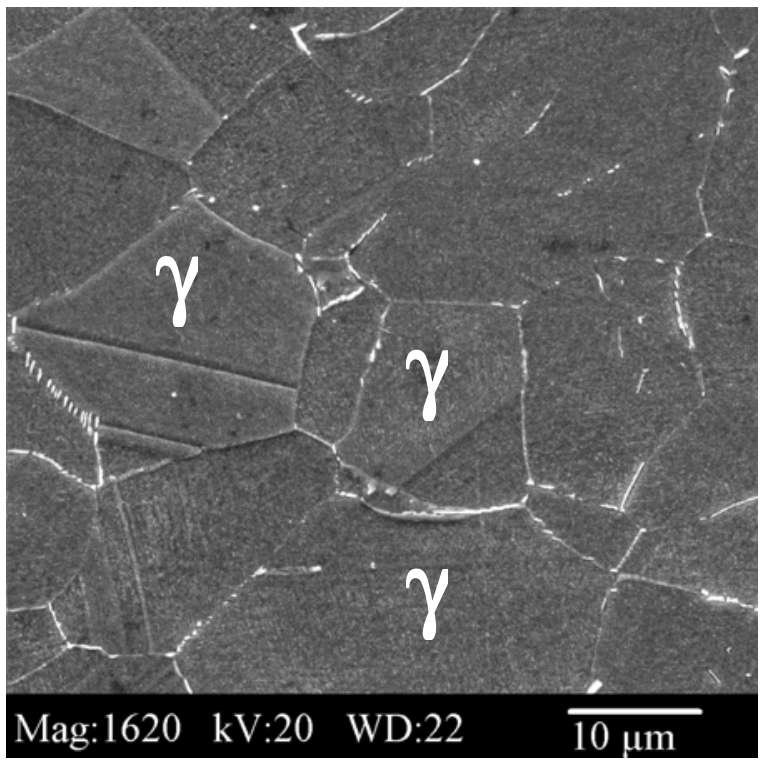

(a)

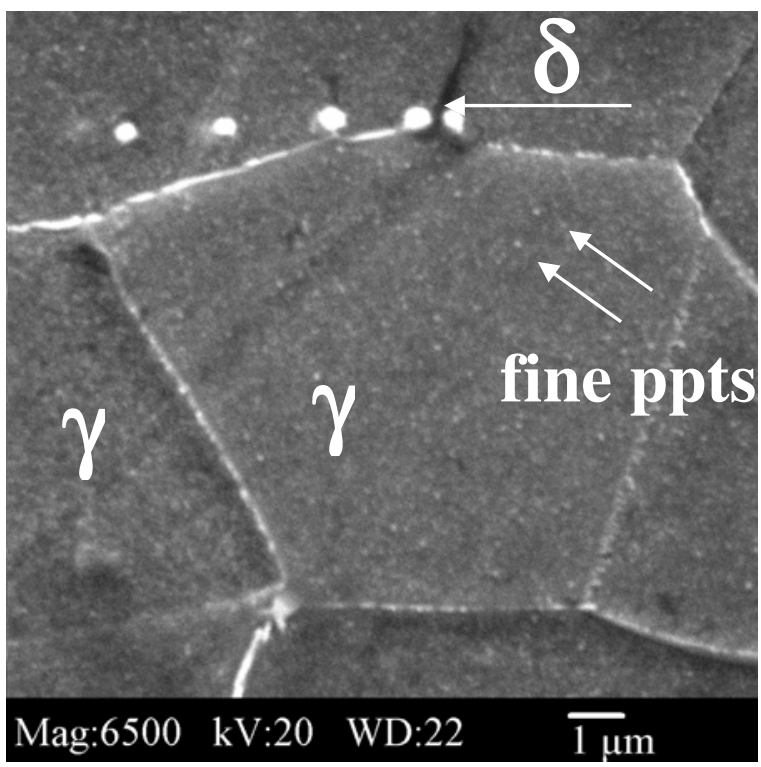

(b)

Figure 1. (a) Low-magnification and (b) high-magnification SEM photomicrographs of the cross-section of a $0 \%$ cold rolled then $954^{\circ} \mathrm{C}$ annealed-then-aged microstructure illustrating the austenitic $\gamma$-phase matrix, fine $\gamma^{\prime}$ and $\gamma^{\prime \prime}$ precipitates, and $\delta$-phase precipitates (white).

\section{$\underline{\text { Creep Behavior }}$}

During the creep experiments the material exhibited normal creep behavior, and the strain-time plots illustrated the three stages of creep: primary, secondary, and tertiary. The dependence of $\dot{\varepsilon}_{\mathrm{ss}}$ on $\sigma_{a}$ is illustrated in Figure 2. The $n_{a}$ values, calculated from the slopes of these curves and listed in Table II, were similar to those observed previously for IN 718 by Han and Chaturvedi [17], whose data were interpolated to $638^{\circ} \mathrm{C}$ and included in Figure 2 and Table II. Their data was for an as-processed condition, and it closely resembled the $0 \% \mathrm{CR}$ data in the current work. Note that the $n_{a}$ values, which ranged between 9-40, were similar to those measured for other particle-strengthened alloy systems [2-14], and are considerably larger than those generally observed for pure metals. It is apparent that there were two clusters of data, where the highest strain rates were exhibited by the samples CR to more than $40 \%$ and lower strain rates were exhibited by the $0-40 \%$ CR samples.

Figure 3 illustrates the plot used to determine $\sigma_{0}$ while Figure 4 illustrates the corresponding $\varepsilon_{\mathrm{ss}}$ versus $\sigma_{\mathrm{e}}$ plot. The values of $\mathrm{n}_{\mathrm{e}}$, listed along with $\varepsilon_{\mathrm{ss}}$ and $\sigma_{\mathrm{o}}$ in Table II, were determined from equation 2 . The $20 \% \mathrm{CR}$ and $30 \% \mathrm{CR}$ samples exhibited the greatest $\sigma_{\mathrm{o}}$ values, 645 and $630 \mathrm{MPa}$, respectively, while the $60 \% \mathrm{CR}, 80 \% \mathrm{CR}$, and IN 718SPF conditions exhibited the lowest $\sigma_{o}$ values, which were less than half those of the highest $\sigma_{o}$ values. Correspondingly the $\varepsilon_{\mathrm{ss}}$ values for a given $\sigma_{\mathrm{a}}$ were the lowest for the $20 \% \mathrm{CR}$ and $30 \% \mathrm{CR}$ materials, see Table II. For $\sigma_{\mathrm{e}}$ less than $135 \mathrm{MPa}$, the $\mathrm{n}_{\mathrm{e}}$ values were between one and two, while for $\sigma_{\mathrm{e}}$ greater than $135 \mathrm{MPa}, \mathrm{n}_{\mathrm{e}}$ was greater than 3.5 , see Table II and Figure 4. The $\mathrm{Q}_{\mathrm{a}}$ value $(304 \pm 10 \mathrm{~kJ} / \mathrm{mol})$ was determined for the $20 \% \mathrm{CR}$ material using the $\ln \varepsilon_{\mathrm{ss}}$ vs $1 / \mathrm{T}$ plot shown in Figure 5. 
Table II. The $638^{\circ} \mathrm{C}$ Creep Data of IN 718 samples annealed at $954^{\circ} \mathrm{C}$ then aged

\begin{tabular}{|c|c|c|c|c|c|c|}
\hline Cold Rolling Deformation, $\%$ & $\sigma_{\mathrm{a}}, \mathrm{MPa}$ & $\sigma_{0}, \mathrm{MPa}$ & $\sigma_{0-} \sigma_{a}, M P a$ & $\varepsilon_{\mathrm{ss}}$ & $\mathbf{n}_{\mathbf{a}}$ & $\mathbf{n}_{\mathbf{e}}$ \\
\hline \multirow{9}{*}{$0 \%$} & 574 & 540 & 34 & 2.1E-09 & 10.8 & 1.2 \\
\hline & 574 & 540 & 34 & 1.9E-09 & 10.8 & 1.2 \\
\hline & 594 & 540 & 54 & 3.5E-09 & 10.8 & 1.2 \\
\hline & 595 & 540 & 55 & 3.8E-09 & 10.8 & 1.2 \\
\hline & 609 & 540 & 69 & 4.4E-09 & 10.8 & 1.2 \\
\hline & 611 & 540 & 71 & 4.6E-09 & 10.8 & 1.2 \\
\hline & 632 & 540 & 92 & 6.0E-09 & 10.8 & 1.2 \\
\hline & 649 & 540 & 109 & 9.1E-09 & 10.8 & 1.2 \\
\hline & 674 & 540 & 134 & 1.1E-08 & 10.8 & 1.2 \\
\hline \multirow{6}{*}{$10 \%$} & 591 & 570 & 21 & 1.0E-09 & 18.3 & 1.7 \\
\hline & 596 & 570 & 26 & 1.1E-09 & 18.3 & 1.7 \\
\hline & 610 & 570 & 40 & 2.8E-09 & 18.3 & 1.7 \\
\hline & 634 & 570 & 64 & 5.1E-09 & 18.3 & 1.7 \\
\hline & 666 & 570 & 96 & 1.1E-08 & 18.3 & 1.7 \\
\hline & 694 & 570 & 124 & $1.9 \mathrm{E}-08$ & 18.3 & 1.7 \\
\hline \multirow{3}{*}{$20 \%$} & 666 & 645 & 21 & 3.8E-09 & 39.8 & 1.7 \\
\hline & 676 & 645 & 31 & 7.3E-09 & 39.8 & 1.7 \\
\hline & 683 & 645 & 38 & 1.0E-08 & 39.8 & 1.7 \\
\hline \multirow{3}{*}{$30 \%$} & 648 & 630 & 28 & 1.5E-09 & 36.0 & 1.7 \\
\hline & 668 & 630 & 38 & 5.6E-09 & 36.0 & 1.7 \\
\hline & 680 & 630 & 50 & 8.4E-09 & 36.0 & 1.7 \\
\hline \multirow{8}{*}{$40 \%$} & 578 & 550 & 28 & $2.4 \mathrm{E}-09$ & 13.7 & 1.5 \\
\hline & 593 & 550 & 43 & 2.9E-09 & 13.7 & 1.5 \\
\hline & 596 & 550 & 46 & 2.8E-09 & 13.7 & 1.5 \\
\hline & 598 & 550 & 48 & 3.3E-09 & 13.7 & 1.5 \\
\hline & 610 & 550 & 60 & 4.7E-09 & 13.7 & 1.5 \\
\hline & 613 & 550 & 63 & 5.2E-09 & 13.7 & 1.5 \\
\hline & 613 & 550 & 63 & 4.8E-09 & 13.7 & 1.5 \\
\hline & 627 & 550 & 77 & 6.6E-09 & 13.7 & 1.5 \\
\hline \multirow{12}{*}{$60 \%$} & 378 & 310 & 68 & 3.3E-09 & 4.6 & 1.0 \\
\hline & 399 & 310 & 89 & 4.2E-09 & 4.6 & 1.0 \\
\hline & 417 & 310 & 107 & 5.2E-09 & 4.6 & 1.0 \\
\hline & 436 & 310 & 126 & 7.2E-09 & 10.4 & 3.6 \\
\hline & 455 & 310 & 145 & 9.9E-09 & 10.4 & 3.6 \\
\hline & 471 & 310 & 161 & $1.2 \mathrm{E}-08$ & 10.4 & 3.6 \\
\hline & 490 & 310 & 180 & $2.0 \mathrm{E}-08$ & 10.4 & 3.6 \\
\hline & 501 & 310 & 191 & 3.3E-08 & 10.4 & 3.6 \\
\hline & 537 & 310 & 227 & $5.8 \mathrm{E}-08$ & 10.4 & 3.6 \\
\hline & 564 & 310 & 254 & 7.9E-08 & 10.4 & 3.6 \\
\hline & 598 & 310 & 288 & $1.2 \mathrm{E}-07$ & 10.4 & 3.6 \\
\hline & 612 & 310 & 302 & 1.3E-07 & 10.4 & 3.6 \\
\hline \multirow{6}{*}{$80 \%$} & 375 & 300 & 75 & 2.3E-09 & 4.5 & 1.1 \\
\hline & 397 & 300 & 97 & 3.0E-09 & 4.5 & 1.1 \\
\hline & 417 & 300 & 117 & 3.8E-09 & 4.5 & 1.1 \\
\hline & 457 & 300 & 157 & $6.0 \mathrm{E}-09$ & 10.3 & 3.9 \\
\hline & 489 & 300 & 189 & 9.7E-09 & 10.3 & 3.9 \\
\hline & 523 & 300 & 223 & $2.4 \mathrm{E}-08$ & 10.3 & 3.9 \\
\hline \multirow{4}{*}{$\begin{array}{c}\text { Han and Chatervedi [17] interpolated } \\
\text { to } 638^{\circ} \mathrm{C}\end{array}$} & 620 & 524 & 96 & 5.9E-09 & 9.0 & 1.9 \\
\hline & 673 & 524 & 149 & $1.2 \mathrm{E}-08$ & 9.0 & 1.9 \\
\hline & 696 & 524 & 172 & 1.7E-08 & 9.0 & 1.9 \\
\hline & 720 & 524 & 196 & 2.3E-08 & 9.0 & 1.9 \\
\hline \multirow{3}{*}{ IN 718SPF } & 334 & 305 & 29 & $2.1 \mathrm{E}-09$ & 5.3 & 1.1 \\
\hline & 374 & 305 & 69 & 3.3E-09 & 5.3 & 1.1 \\
\hline & 405 & 305 & 100 & 6.0E-09 & 5.3 & 1.1 \\
\hline
\end{tabular}




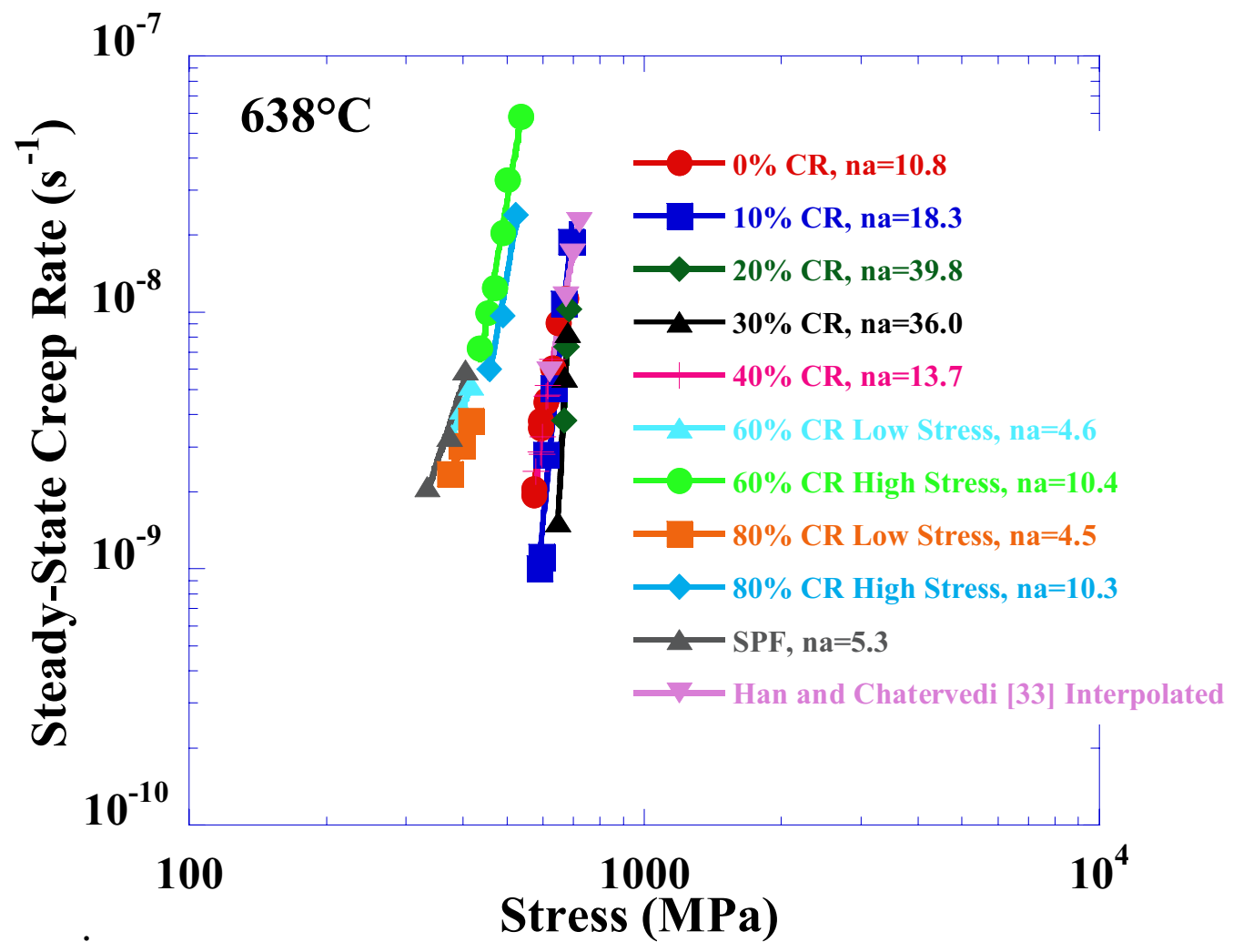

Figure 2. $\varepsilon_{\mathrm{ss}}$ versus $\sigma_{\mathrm{e}}$ plot for the $954^{\circ} \mathrm{C}$ annealed-then-aged $\mathrm{IN} 718$ creep samples tested at $638^{\circ} \mathrm{C}$. Also included is data from Han and Chaturvedi [33] which has been interpolated to $638^{\circ} \mathrm{C}$.

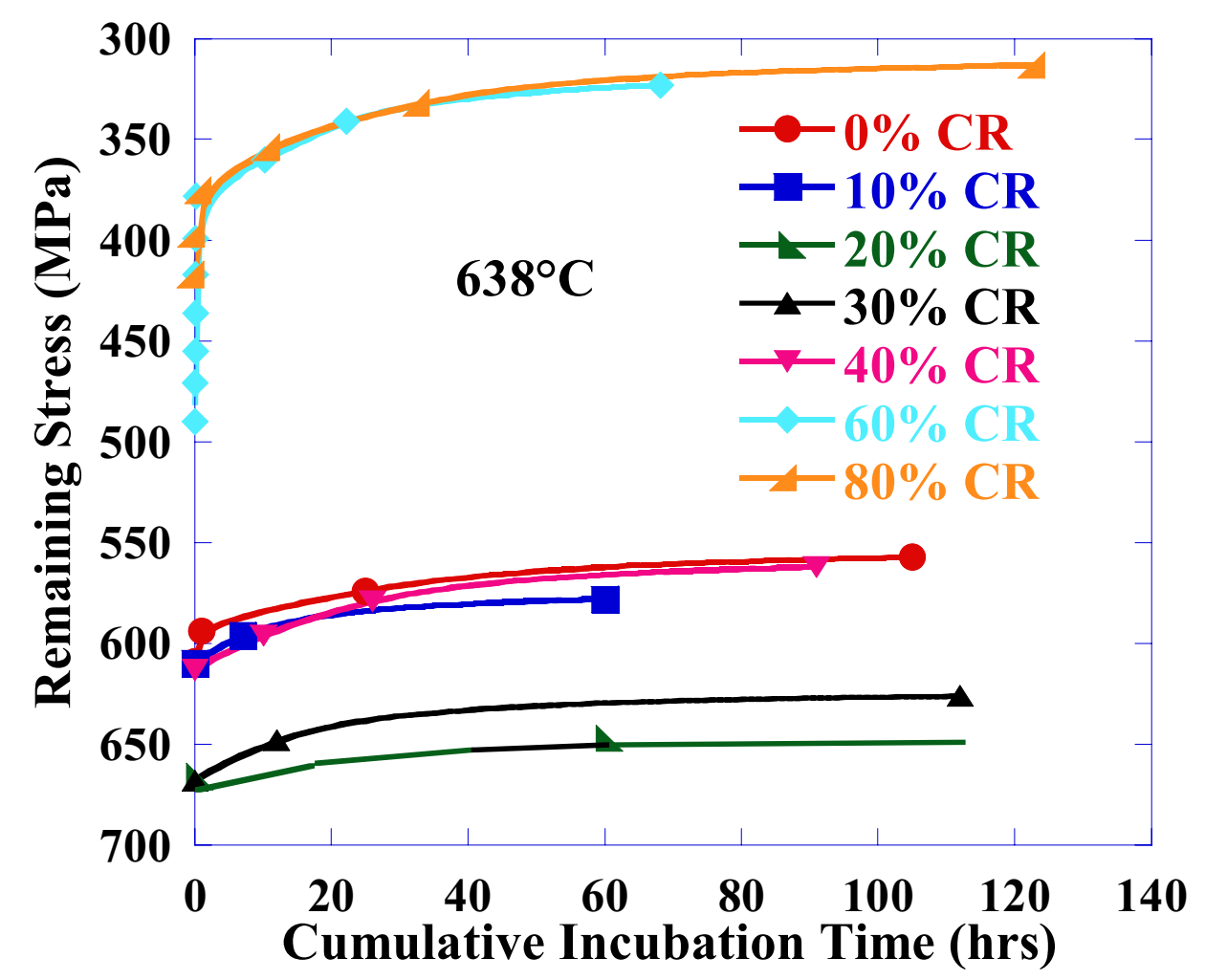

Figure 3. Remaining stress versus cumulative incubation time for the cold rolled and $954^{\circ} \mathrm{C}$ annealed-then-aged IN 718 creep samples. 


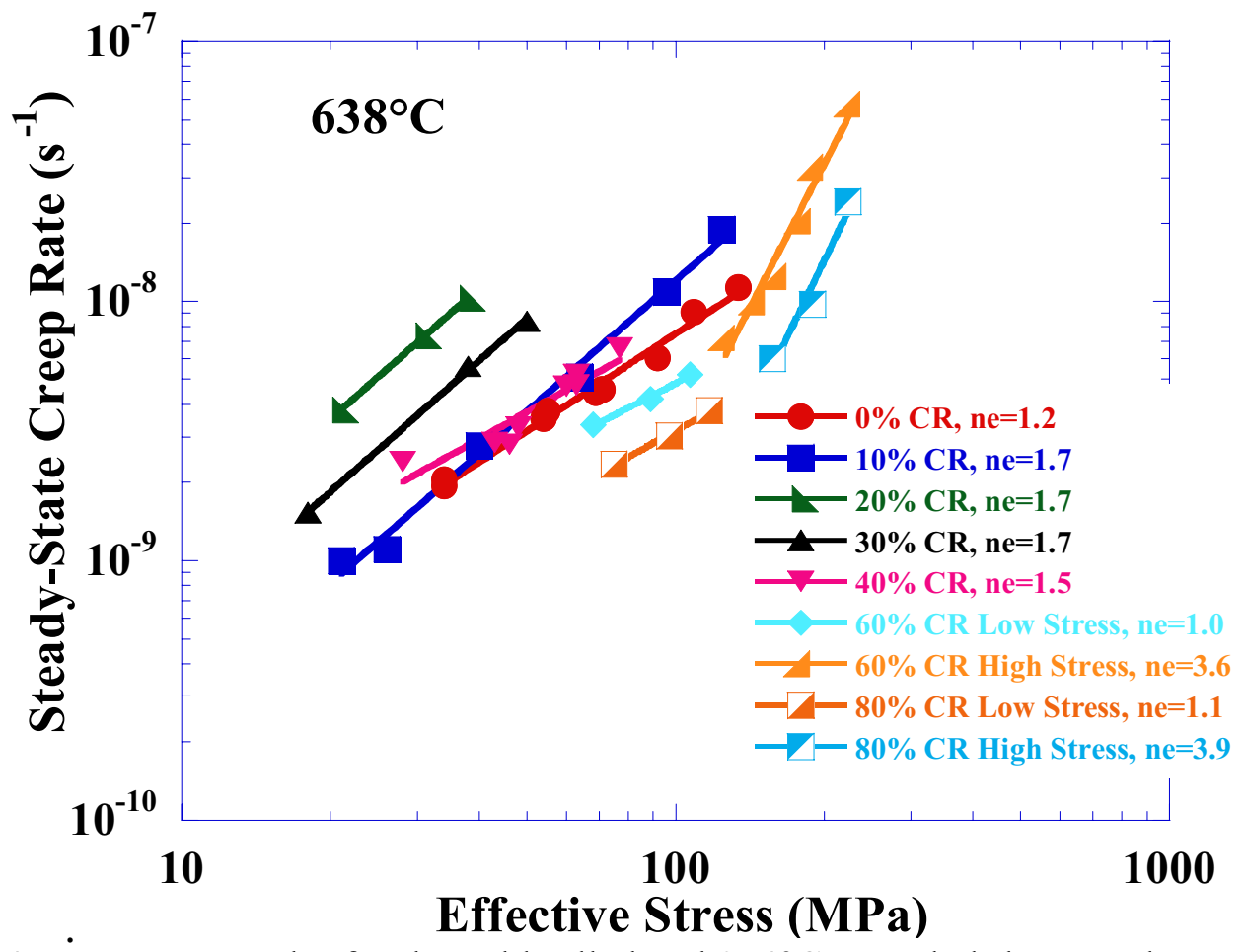

Figure 4. $\varepsilon_{\mathrm{ss}}$ versus $\sigma_{\mathrm{e}}$ plot for the cold rolled and $954^{\circ} \mathrm{C}$ annealed-then-aged IN 718 samples. The data was used to calculate the listed $\mathrm{n}_{\mathrm{e}}$ values.

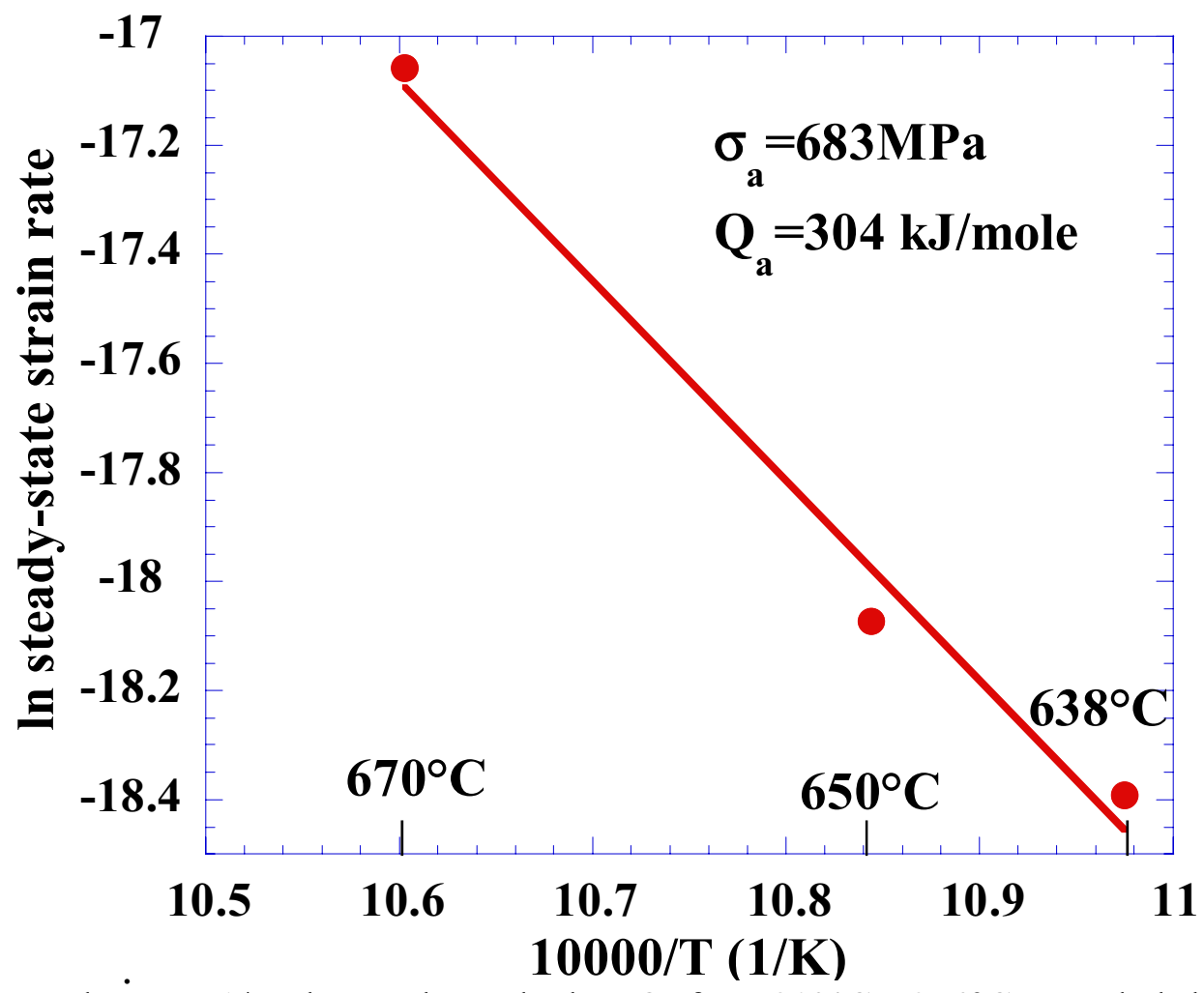

Figure 5. $\ln \dot{\varepsilon}_{\mathrm{ss}}$ vs $1 / \mathrm{T}$ plot used to calculate $\mathrm{Q}_{\mathrm{a}}$ for a $20 \% \mathrm{CR} 954^{\circ} \mathrm{C}$ annealed-then-aged sample.

The creep rupture data, listed in Table III, indicated that increased CR tended to increase $\mathrm{T}_{\mathrm{r}}$. For the $954^{\circ} \mathrm{C}$ annealed-then-aged samples, the greatest $\mathrm{T}_{\mathrm{r}}$ and $\varepsilon_{\mathrm{f}}$ values were exhibited by the $30 \%$ and $40 \%$ cold rolled samples, where both the $\mathrm{T}_{\mathrm{r}}$ and $\varepsilon_{\mathrm{f}}$ values were greater than twice those for the baseline $0 \%$ and $10 \% \mathrm{CR}$ conditions. Cold rolling below $30 \%$ did not offer as significant of an increase in the creep rupture properties and both the $10 \%$ and $20 \% \mathrm{CR}$ 
conditions resulted in lower $\varepsilon_{\mathrm{f}}$ values than that for the baseline $0 \% \mathrm{CR}$ condition. Each of the ruptured samples exhibited ductile dimpling throughout the fractured surface. The $871^{\circ} \mathrm{C}$ annealed-then-aged samples tended to exhibit increased $T_{r}$ values with increased $C R$ and the $T_{r}$ values were significantly greater than the $954^{\circ} \mathrm{C}$ annealed-then-aged samples. This is considered to be a result, in part, to the greater tensile strengths exhibited by the $871^{\circ} \mathrm{C}$ heat-treated materials.

Table III. Creep rupture properties $\left(649^{\circ} \mathrm{C} / 758 \mathrm{MPa}\right)$ for heat-treated $\left(* 954^{\circ} \mathrm{C}, * * 871^{\circ} \mathrm{C}\right)$ samples

\begin{tabular}{|c|c|c|c|c|}
\hline Cold Rolling Deformation, $\%$ & $\mathrm{~T}_{\mathrm{r}}{ }^{*}, \mathrm{hr}$ & $\varepsilon_{\mathrm{f}}, * \%$ & $\mathrm{~T}_{\mathrm{r}}{ }^{*}, \mathrm{hr}$ & $\varepsilon_{\mathrm{f}}, * * \%$ \\
\hline 0 & 24.9 & 9.3 & 73.6 & 26.1 \\
\hline 10 & 27.5 & 6.7 & 65.7 & 25.2 \\
\hline 20 & 38.5 & 7.9 & 99.8 & 22.0 \\
\hline 30 & 64.8 & 28.9 & 103.8 & 18.2 \\
\hline 40 & 57.9 & 38.0 & 128.9 & 23.8 \\
\hline
\end{tabular}

\section{Discussion}

\section{Creep Behavior}

Effective stress exponent According to Wilshire and coworkers [2,4,5] and Gibeling and Nix [19], the consecutive stress reduction method can be used to measure $\sigma_{0}$ during dislocation power-law creep where an incubation time after a small stress reduction is observed to occur. However, for IN 718 Han and Chaturvedi [16,17] observed an incubation time in both the power-law and the diffusional-creep regimes. According to Harris [28] and Burton [29], for diffusional creep to continue, the stress concentration at the precipitate-matrix interface created by the entrapment of diffusing vacancies can only be relieved by the formation of prismatic dislocation loops. However, Ansel and Weertman [30] have suggested that diffusional creep in two-phase alloys can only occur by the process of dislocation climb over the precipitate particles. Therefore diffusional creep in two-phase alloys may not only involve vacancy diffusion in the matrix and dislocation motion in the grain boundary region but also dislocation creation and motion within grains. Similar to the process of dislocation slip during power-law creep, dislocation climb during diffusion creep also requires dislocation networks or line segments to grow to a sufficient length so that they can be activated. These dislocation segments which become active are known as Bardeen-Herring sources [31]. Han and Chaturvedi [16] observed dislocation networks within grains where it was suggested that the observed incubation time could be due to the activation of these Bardeen-Herring sources. Therefore it was concluded that the consecutive stress reduction method can be used to determine $\sigma_{0}$ during power-law creep as well as diffusional-creep.

The experimental results of the current work indicate two separate regimes based on the effective stress level. The $n_{\mathrm{e}}$ values were measured to be between one and two for $\sigma_{\mathrm{e}}$ less than $135 \mathrm{MPa}$, and $\mathrm{n}_{\mathrm{e}}$ was 3.6-3.9 for $\sigma_{\mathrm{e}}$ greater than $135 \mathrm{MPa}$. Based on this result, the creep mechanism may be dependent on $\sigma_{\mathrm{e}}$, and the low-stress regime $\left(\sigma_{\mathrm{a}}<450 \mathrm{MPa}\right)$ may be dominated by diffusional creep or grain boundary sliding. The mechanism of diffusional creep in particlestrengthened alloys is different from that of single-phase alloys or pure metals. Diffusional creep in the latter is known to be the result of stress-induced diffusion or the migration of matter from grain boundaries that are in tension to those that are in compression. In contrast, in particlestrengthened alloys, diffusion of vacancies will be inhibited by the precipitate particles with an accumulation of vacancies at the precipitate-matrix interface and a resultant build-up of stress concentration. This stress concentration at the interface can be relaxed by the punching of prismatic dislocation loops in the matrix, which can annihilate themselves by the absorption of 
vacancies $[28,29]$. Therefore, to accommodate even very limited diffusional strain, in particlestrengthened alloys, additional plastic deformation must occur around precipitates either in the grain boundary region or within grains, giving an $n_{e}$ value slightly greater than 1 . Furthermore, diffusional creep can involve the process of dislocation climb over the particles [30]. Ansel and Weertman [30] considered the rate controlling process to be the climb of dislocations over the precipitate particles, which also depends on the diffusion rate. However, if cross-slip is also important in the above process, the creep rate will be more sensitive to stress. Han and Chaturvedi [17] observed dislocation segments and loops within grains even under the testing conditions where they considered diffusional creep to occur. Their observations suggest that the creep is more sensitive to the applied stress in particle-strengthened alloys than to that in pure metals; i.e. the value of $n_{e}$ can be slightly greater than 1 . This observation is in agreement with the findings of Ansel and Weertman [30], and it may also help explain the $n_{e}$ values of the current work.

Activation energy The measured $\mathrm{Q}_{\mathrm{a}}$ value $(304 \mathrm{~kJ} / \mathrm{mol})$ was greater than both the activation energy for self diffusion $(265-280 \mathrm{~kJ} / \mathrm{mol})$ and the activation energy for the creep process $(276 \mathrm{~kJ} / \mathrm{mol})$ of pure $\mathrm{Ni}$ [32] and the creep process of $\mathrm{Ni}-\mathrm{Cr}$ in solid solution $(295 \mathrm{~kJ} / \mathrm{mol})$ [33]. However, the creep rate expression used to calculate these values considers neither the influence of temperature on the value of $\mathrm{G}$ nor the concept of backstress. Using the backstress, lower activation energies than those calculated using the applied stress have been calculated [17], and such values lie within the range expected for lattice self diffusion. Thus a similar result would be expected based on the $\mathrm{Q}_{\mathrm{a}}$ measured here, and self-diffusion is considered to be more likely than grain boundary diffusion for creep of IN 718 in the temperature range of $638-670^{\circ} \mathrm{C}$

Backstress The significant drop in $\sigma_{0}$ with increased CR deformation beyond $40 \%$ was correlated with a decreasing average grain diameter of approximately $20 \mu \mathrm{m}$ for the baseline $0 \% \mathrm{CR}$ material to approximately $6 \mu \mathrm{m}$ for the $60 \% \mathrm{CR}, 80 \% \mathrm{CR}$, and IN $718 \mathrm{SPF}$ microstructures. The $\sigma_{\mathrm{o}}$ values observed in the current work suggest that $\sigma_{\mathrm{o}}$ may be dependent on grain size. At this point, the reason for the dramatic increase in backstress for the $20 \% \mathrm{CR}$ and $30 \% \mathrm{CR}$ conditions is not apparent and observations of the deformed samples are necessary.

Creep rupture Increased CR tended to increase $T_{\mathrm{r}}$ and $\varepsilon_{\mathrm{f}}$. The IN 718SPF material was not evaluated in creep in this study, but based on previous creep rupture data [22] its $T_{r}$ value is expected to be similar to that exhibited by the $20 \% \mathrm{CR}$ condition. Thus there appears to be a limit to the amount of CR deformation that will result in increased creep rupture life and $\varepsilon_{\mathrm{f}}$. This limit appears to be near 30\% $\mathrm{CR}$ as this condition exhibited the maximum $\mathrm{T}_{\mathrm{r}}$ value and a decrease in $\mathrm{T}_{\mathrm{r}}$ was observed at $40 \% \mathrm{CR}$ for the $954^{\circ} \mathrm{C}$ annealed-then-aged samples. It is noted that a significant decrease in the grain size occurred with increased CR from the $40 \% \mathrm{CR}$ condition to the IN 718SPF condition, and this may be a significant factor in the creep rupture discrepancy. Comparing the creep strain rate and rupture properties, it appears that the $30 \% \mathrm{CR}$ condition results in the most attractive overall creep behavior.

\section{Summary}

IN 718 was processed through sequential increments of CR between $0-80 \%$ followed by annealing and aging to evaluate processing-creep property relationships. The steady-state creep rate, backstress, and creep-rupture properties were measured for $954^{\circ} \mathrm{C}$ annealed-then-aged samples. The greatest backstress and lowest creep rate values were exhibited by the $20 \%$ and $30 \% \mathrm{CR}$ microstructures. The lowest backstress and greatest creep rates were exhibited by the most severely CR microstructures which exhibited the finest grain size. The effective stress 
exponent values, which incorporated the backstress, suggested that the creep deformation mechanism is dependent on effective stresses $\left(\sigma_{\mathrm{e}}\right)$ where the transition point occurs at $\sigma_{\mathrm{e}} \sim 135 \mathrm{MPa}$. Trends in the creep rupture data indicated that both $\mathrm{T}_{\mathrm{r}}$ and $\varepsilon_{\mathrm{f}}$ increases with increased CR. Overall, the $30 \% \mathrm{CR}$ condition exhibited the most attractive creep properties.

\section{Acknowledgments}

This work was supported by the NSF Division of Materials Research (DMR-0134789). The authors acknowledge Gaylord Smith (SMC) and James Crum (SMC) for helpful guidance.

\section{$\underline{\text { References }}$}

1. A.K. Mukherjee, J.E. Bird, and J.E. Dorn: Trans. Am. Soc. Metals, 1969, vol. 62, pp. 155-79.

2. K.R. Williams and B. Wilshire: Met. Sci. J., 1973, vol. 7, pp. 176-9.

3. D. Sidney and B. Wilshire: Met. Sci. J., 1969, vol. 3, pp. 56.

4. J.D. Parker and B. Wilshire: Met. Sci. J., 1975, vol. 9, pp. 248.

5. P.W. Davies, G. Nelmes, K.R. Williams, and B. Wilshire: Met. Sci. J., 1973, Vol. 7, pp 87-92.

6. W.J. Evans and G.F. Harrison: Met. Sci. J., 1976, vol. 10, pp. 307.

7. R. Lagneborg and B. Bergman: Met. Sci. J., 1976, vol. 10, pp. 20.

8. D.D. Sherby and P.M. Burke: Prog. Mater. Sci., 1967, vol. 13, pp. 325.

9. J.D. Parker and B. Wilshire: Metal Science, October 1978, pp. 453-8.

10. R. Lund and W.D. Nix: Acta Metall., 1976, vol. 24, pp. 469.

11. C.N. Ahlquist and W.D. Nix: Acta Metall 1971, vol. 19, pp. 373-85.

12. C.L. Meyers, J.C. Shyne, and O.D. Sherby: Aust. Inst. Met., 1963, vol. 8, pp. 171.

13. B.A. Wilcox and A.H. Clauer: Trans. Metall. Soc. AIME, 1966, vol. 236, pp. 570

14. A.H. Clauer and B.A. Wilcox: Met. Sci. J., 1967, vol. 1, pp. 86.

15. B.A. Wilcox and A.H. Clauer: Met. Sci. J., 1969, vol. 3, pp. 26.

16. Y. Han and M.C. Chaturvedi: Mater. Sci. Eng., 1987, vol. 85, pp. 59-65.

17. Y. Han and M.C. Chaturvedi: Mater. Sci. Eng., 1987, vol. 89, pp. 25-33.

18. W. Chen and M.C. Chaturvedi: Materials Science and Engineering, 1994, vol. A183, p 81-9.

19. J.C. Gibeling and W.D. Nix: Materials Science and Engineering, 1980, vol. 45, p.123.

20. S. Purushothman and J.K. Tien: Acta Materialia, 1978, vol. 26, pp. 519.

21. J.H. Hausselt and W.D. Nix: Acta Materialia, 1977, vol. 25, pp. 595.

22. G.D. Smith and D.H. Yates: Proc. Advancements in Synthesis and Processes, 1992, Society for the Advancement of Material and Process Engineering, Covina, CA, pp. M207-M218.

23. G.D. Smith and H.L. Flower: Proc. Superalloys 718, 625, 706 and Various Derivatives, 1994, The Minerals, Metals and Materials Society, Warrendale, PA, pp. 355-364.

24. B.A. Baker: INCO Alloys International Technical Investigation Report No. BAB1323093, Huntington, WV. September 1993.

25. Y. Huang and P.L. Blackwell: Materials Science and Technology, 2003, Vol. 19, pp. 461-6.

26. INCONEL alloy 718 Bulletin, $4^{\text {th }}$ Edition, 1985, published by The International Nickel Company, Inc., now Special Metals Corporation, p.1-25

27. W.C. Liu, Z.L. Chen, and M. Yao: Metall. and Materials Transactions, 1999, 30A, p 31-40.

28. J.E. Harris: Met. Sci. J., 1973, vol. 7, p.1.

29. B. Burton: Materials Science and Engineering, 1973, vol. 11, pp. 337.

30. G.S. Ansel and J. Weertman: Trans. Metall. Soc. AIME, 1959, vol. 215, p.838.

31. D. Hull: Introduction to Dislocations, Pergamon, Oxford, 1975, pp.188-190

32. J.P. Dennison, R.J. Llewellyn, and B. Wilshire: J. Inst. Met., 1967, vol. 95, p.115.

33. D. Sidey and B. Wilshire, Met. Sci. J., 1969, vol. 3, p.56. 